\title{
An Estimation of Tree Species Diversity in Rural Farmland of Nepal
}

\author{
Deepak K. Kharal ${ }^{1}$ and Bishwa N. Oli ${ }^{2}$
}

\begin{abstract}
Biodiversity is an important consideration in maintaining natural environmental balance in a particular habitat. This becomes particularly important in areas, where due to the encroachment of natural forests, biodiversity is depleting causing a potential loss in the natural habitat. In such a situation, biodiversity in the farmland becomes an important consideration. Biodiversity is measured and analyzed using various indices. In this study, we present the result of our study through a field work in a rural village in Nepal. The study was conducted through direct field observation and survey of sampled households. The status of tree biodiversity using species biodiversity index and species richness index for the case study are presented. The study has also identified the relationship between the tree species diversity and major socioeconomic factors. Our analysis shows that tree species biodiversity in the rural farmland of study area are lower in comparison to the similar areas of countries like India, Bangladesh and Sri Lanka. The lower biodiversity status is mainly due to the wide distribution of two dominating tree species of Dalbergia sissoo and Melia azederach. Similarly, Tree species biodiversity in the farm land has been found affected by the socioeconomic situation of the area. Further study is suggested by involving more socioeconomic factors and covering a large sample size and time of study.
\end{abstract}

Key words: Farmland, Forest, Homegarden, Nepal, Species Diversity, Species Richness, Trees.

$\mathbf{D}$ eforestation, one of the biggest environmental problems, need to be contained to conserve the diversity of trees as well as other plant and animal species in natural ecosystem (Mishra, 1998). However, in Nepal, in a period of about 15 years (1979 to 1994), nearly one and half million hectares of forest land were lost for fuel, agriculture activities and settlements giving a cumulative loss of about $1.7 \%$ of forest areas in an annual basis (DFRS, 1999). This process is still continuing in the remaining forest patches. This is quite an alarming situation for a mountainous country like Nepal, whose economic output largely depends on agricultural and forest based activities.

When the natural forests are in the verge of extinction, farmland plays significant role in the species conservation. As deforestation continues, along with the increase of population, it will be extremely difficult to conserve biodiversity in the isolated island of forest (Wickramasinghe, 1995). Due to natural habitat loss, several species have been threatened or reached to the point of extinction in the absence of immediate conservation action (Brooks et al, 2001, Mishra, 1998). As it has been difficult to contain deforestation except for those places where forests are protected, researchers are diverting their attention to farm lands as potential reservoir to maintain the biodiversity level in an area. Traditional agro-ecosystems are particularly rich in sources of both biodiversity and indigenous knowledge about its management. Farmers have different needs on resources. For example, they tend to fulfill their needs for fruits, fodder, fuelwood, timber, medicine, gardening, religious activities, and other environmental protection from bio-resources around them. Therefore, such needs cannot be fulfilled by a few species only. Also, as the farm size are small but supports the family's economic and culinary activities, farmers tend to increase biodiversity to protect themselves against the risk of failing some species. Halladay and Gilmour (1995) found that such a traditional system could facilitate the conservation of genetic diversity outside the forested lands. Biodiversity also helps in maintaining

\footnotetext{
${ }^{1}$ Forest Survey Officer, Department of Forest Research and Survey, P. O. Box 3339 Kathmandu, Nepal. Corresponding author, Email:dkharal@wlink.com.np

${ }^{2}$ Forest Research Officer, Department of Forest Research and Survey P. O. Box 3339 Kathmandu, Nepal. Email: bn_oli@yahoo.com
} 
stability and resilience. Therefore, the policy planners would have to understand not only the biodiversity of the natural forests, but help to increase their index in the farmlands as well so that not only the natural habitat of species is extended, but also support the livelihood of the households in the rural areas. However, to implement such a policy, it is necessary to understand the existing biodiversity levels in terms of species diversity index and species richness index of trees on rural farmlands. Such an index could also be linked to socioeconomic factors to better understand the impact of biodiversity on the rural population.

\section{Materials and methods}

\section{Study area}

This study was conducted in a rural village of Chitwan district in Nepal. This village has been selected mainly due to diverse community structure and land use type so that comparison among the different categories of each socio-economic variable can be analyzed easily. The community is diverse particularly in terms of ethnic group, time of settlement, economic level and occupation. The village has natural forest mainly dominating by Shorea robusta forest some part of which are managed by community forest user groups and remaining are controlled by government agency itself. East-west national highway of the country touches in southern part of the village with semi urban characteristics whereas typical rural settlements and natural forest are found in northern part.

\section{Sampling methods}

The study was carried out in 98 households of the Birendranagar Village Development Committee (VDC) of the Chitwan district, Nepal. The VDC is the lowest unit of local government structure. The field work took about six months and completed in 2000. The preliminary field work was aimed to observe the community structure, land use type, vegetation and other socio-economic condition of the area. A semi-structure questionnaire was used for formal household survey under the stratified random sampling techniques. The study considered each Ward number of the VDC as a single stratum resulting total nine strata in the whole study area. Sampled household in each stratum was identified through random walk by which first household was selected randomly and subsequent households were selected in a regular interval of 20 to maintain $5 \%$ sampling intensity for the study. An interval of 20 households along the walk was maintained to avoid bias in responses and to obtain as much diversity in the responses as possible. Field observation was done simultaneously to assess the distribution of tree species inside the farmland. All the individuals of each tree species (above 1.3 meters height) were counted regardless of their age in the farmland belonging to the sampled household. A group of early residents of the area in each strata of the study area was consulted to understand the dynamics of tree species in their farmland. Problems and constraints, in terms of biodiversity of tree species in the area, were taken during the consultation.

\section{Estimation of Species Diversity Index (SDI)}

The species diversity index for the average farmland and total study area were calculated by using a specific method $\left(\mathrm{H}^{\prime}=-\Sigma \mathrm{Pi} \mathrm{x} \ln \mathrm{Pi}\right)$ as suggested by Shannon and Weaver (1949). H' refers to the index value of biodiversity whereas Pi refers to the proportion of all individuals of ith species against the all individuals of all tree species. The Shannon diversity index for the natural communities is often found to fall between 1.0 to 6.0. The maximum diversity of a sample is obtained when all species are equally abundant and is represented as $\mathrm{H}_{\max }$ (Stilling, 1996).

\section{Estimation of Species Richness Index (SRI)}

Species richness are generally measured in terms of a ratio of total number of species and total number of individuals of all species of a specified area. It gives more priority to the number of species rather than number of individuals. By this method, increasing a few numbers of individuals within a species gives higher value of index than the increasing large number individuals within the species. It means higher the number of individuals in a species lowers the species richness index of a given community. This study used Margelef (1969) method (R = S-1/Ln N1) while assessing the SRI of the trees both at individual farmland and the total study area level. Here R stands for Richness Index of tree species, $\mathrm{S}$ stands for total number of tree species and $\mathrm{N}$ stands for total number of individuals of all tree species of the area.

\section{Categorization of the variables}

We observed many socio economic variables to understand their relationship with the SDI and SRI. Annex 1 gives the list of variables and their categorization including the ranges and numbers of sampled households. Variables were categorized into 
different groups according to their distribution pattern found in the study area. Most of the variables were categorized into three groups so that difference among them can be shown clearly. The critical values for categorizing the variable and their number of categories were identified after field survey during the analysis.

\section{Data Analysis}

The data were analyzed using MS-Excel, Minitab and MS-Access for data compilation, regrouping and developing regression and correlation between various factors being examined. Analysis of variance (ANOVA) was applied to find the impact of variables on species diversity, species richness, tree density, tree per capita, average species holding and average tree holding. The results of the analysis are presented below.

\section{Results}

\section{Status of Tree Species Biodiversity}

Species diversity index and species richness index of the tree resources of the study area were 1.80 and 5.01 respectively. Table 1 below shows the descriptive information on species diversity, species richness, number of species and number of trees in the study area. A total of 60 tree species were found in all sampled farmlands in the study area. The analysis shows that average species per household is about 8 with a maximum value of 30 . Average number of individual tree within a species is about 2148 for all areas, whereas this figure comes to 9 in case of the average household level. The result shows that some households have higher value of diversity and richness indices compared to the value of all study area. The formula is designed in such a way so that the value of species diversity index comes higher once the number of tree individuals of all available species is nearly equal.

Diversity and richness indices by categories of tree species are provided in table 2 . The principle uses of tree species were considered for their categorization. However, some tree species were accounted into two categories based on their prime use. Both the SDI and SRI of the fodder species were higher than other types of the tree species in the area. It is to be noted that species richness is directly proportional to the species number and inversely proportional to the tree number.

\section{Socio Economic Impacts on Biodiversity}

Several factors determine the status of biodiversity at various levels. Household and/or farmland are the smallest unit of biodiversity management. Other level of the management could be a watershed/catchment area, natural landscape/seascape, topographical, physiographic and ecological region etc. Some factors are crucial for species diversity management and others may affect less. Socioeconomic factors are the most important to be considered in farm and/or

Table 1: Species diversity and species richness of the area

\begin{tabular}{lccccc}
\hline \multirow{2}{*}{\multicolumn{1}{c}{ Description }} & \multicolumn{5}{c}{ Descriptive information on tree biodiversity } \\
\cline { 2 - 6 } & Total & Average/HH & Min. & Max. & Std \\
\hline Species Diversity Index (H') & 1.80 & 1.35 & 0.00 & 3.07 & 0.75 \\
Species Richness Index (R) & 5.01 & 2.00 & 0.00 & 6.32 & 1.24 \\
Number of species (S) & 60.0 & 7.70 & 0.00 & 30.00 & 5.69 \\
Number of trees (N) & 128864 & 66.70 & 0.00 & 1514 & 183.20 \\
\hline
\end{tabular}

Source: Field survey; 2000

$\mathrm{HH}=$ Household, Max. = Maximum, Min. = Minimum, Std = Standard Deviation,

Table 2: Diversity and species richness of tree species type

\begin{tabular}{|c|c|c|c|c|c|}
\hline \multirow[b]{2}{*}{ Description } & \multicolumn{5}{|c|}{ Species type } \\
\hline & Fruit & Fodder & $\begin{array}{l}\text { Timber/ } \\
\text { Furniture }\end{array}$ & Fuel wood & Other \\
\hline Species Diversity Index $\left(\mathrm{H}^{\prime}\right)$ & 0.20 & 0.37 & 0.31 & 0.20 & 0.05 \\
\hline Species Richness Index (R) & 2.87 & 4.40 & 0.12 & 0.47 & 1.43 \\
\hline Number of species $(\mathrm{S})$ & $19.0(2.6)$ & $29.0(4.9)$ & $7.0(0.5)$ & $9.0(1.4)$ & $7.00(0.3)$ \\
\hline Trees per $\mathrm{HH}$ & 5.40 & 23.3 & 38.90 & 51.70 & 0.60 \\
\hline
\end{tabular}

Source : Field survey, 2000

Note : Figure in bracket gives the average number per household

: Some species were ccounted in more than one category based on their prime use. 
Table 3: Impact of socioeconomic factors on biodiversity

\begin{tabular}{|c|c|c|c|}
\hline Variables & Categories of Variables & $\begin{array}{l}\text { Average value of SDI of each } \\
\text { category of variable }\end{array}$ & $\begin{array}{c}\text { Average value of SRI of each } \\
\text { category of variable }\end{array}$ \\
\hline Farm size & Small - Medium - Large & $\begin{array}{c}1.12-1.54-1.63 \\
(\mathrm{P}=0.016)\end{array}$ & $\begin{array}{c}1.55-2.27-2.97 \\
(\mathrm{P}=0.001)\end{array}$ \\
\hline Homegarden size & Small - Medium - Large & $\begin{array}{c}1.12-1.70-1.89 \\
(\mathrm{P}=0.00)\end{array}$ & $\begin{array}{c}1.52-2.55-3.71 \\
(\mathrm{P}=0.00)\end{array}$ \\
\hline Livestock size & Small - Medium - Large & $\begin{array}{c}0.8-1.5-1.4 \\
(\mathrm{P}=0.001)\end{array}$ & $\begin{array}{c}1.2-2.1-2.3 \\
(\mathrm{P}=0.001)\end{array}$ \\
\hline $\begin{array}{l}\text { Fuelwood } \\
\text { consumption }\end{array}$ & Low - Fair - High & $\begin{array}{c}1.21-1.31-1.67 \\
(\mathrm{P}=0.082)\end{array}$ & $\begin{array}{c}1.74-1.96-2.52 \\
(\mathrm{P}=0.073)\end{array}$ \\
\hline Income Class & Low - Medium - High & $\begin{array}{c}1.26-1.53-1.26 \\
(\mathrm{P}=0.25)\end{array}$ & $\begin{array}{c}1.74-2.37-2.18 \\
(\mathrm{P}=0.059)\end{array}$ \\
\hline $\begin{array}{l}\text { Major Income } \\
\text { sources }\end{array}$ & $\begin{array}{l}\text { Agriculture - Labor - Business - } \\
\text { Service - Pension }\end{array}$ & $\begin{array}{c}1.56-0.96-1.68-1.11-1.32 \\
(\mathrm{P}=0.02)\end{array}$ & $\begin{array}{c}2.38-1.36-2.44-1.55-1.85 \\
(\mathrm{P}=0.01)\end{array}$ \\
\hline Forest distance & Near - Medium - Far & $\begin{array}{c}1.40-1.38-1.15 \\
(\mathrm{P}=0.48)\end{array}$ & $\begin{array}{c}2.00-2.05-1.82 \\
(\mathrm{P}=0.80)\end{array}$ \\
\hline Caste & $\begin{array}{l}\text { Bramin - Chhetri - Other - } \\
\text { Lower }\end{array}$ & $\begin{array}{c}1.99-2.46-1.81-2.64 \\
(\mathrm{P}=0.383)\end{array}$ & $\begin{array}{c}7.8-10.5-6.8-7.0 \\
(P=0.341)\end{array}$ \\
\hline Settlement period & Early - Middle - New & $\begin{array}{c}0.89-1.21-1.42 \\
\quad(P=0.14)\end{array}$ & $\begin{array}{c}1.19-1.83-2.10 \\
(\mathrm{P}=0.12)\end{array}$ \\
\hline
\end{tabular}

Source : Field survey, 2000

Note : Sample numbers and ranges of each category is presented in annex 1

household biodiversity management. Species diversity, size, shape and plant density also vary from place to place depending on cultural, ecological and socio-economic factors (Soemarwoto, 1987). Tree planting and use were found to be correlated with socio-economic factors such as ethnic group, economic level and farm size (Karki and Karki, 1994).

Single factor hardly determines the level of biodiversity completely. However, it is also true that some factors could influence more than others. As shown in Table 3, both species diversity index and species richness index are significant among the categories of the farm size, homegarden size, livestock holding size and types of income sources. Whereas, both index are not significantly different among the different categories of income class, fuelwood consumption, settlement period, forest distance and caste.

Both SDI and SRI are significantly different among the small, medium and large categories of farm size. However, no strong linear relationship exists between the species diversity and farm size $\left(\mathrm{r}^{2}=0.028, \mathrm{n}=\right.$ 98). It implies that farm size alone is not the powerful determinant of the species diversity. Home garden size significantly affects tree species diversity and species richness, even though no strong linear relationship exist between homegarden size and species diversity $\left(\mathrm{r}^{2}=0.19, \mathrm{n}=98\right)$. Livestock has great influence on species diversity, species richness, tree number and tree species number in rural households of Nepal. Although large number of trees are required to support the large number livestock, our study shows that livestock is also not a powerful determinant for tree biodiversity $\left(\mathrm{r}^{2}=0.06\right.$, $\mathrm{n}=98$ ). Large herds of livestock are found in higher income household and large farm holders. Fuelwood consumption alone does not influence much in species diversity of the farmland, though little difference is found among the categories. Even the linear relationship between fuelwood consumption and species diversity is not strong $\left(\mathrm{r}^{2}=0.051, \mathrm{n}=\right.$ 98). Although the difference is not significant, large number of trees and species are generally found in households with high fuelwood consumptions. As a result, high fuelwood consumption may be problem in other areas, but it encourages farmers to maintain large number of trees in the farmland.

Difference in the species diversity, species richness and tree density are not significant among the categories of the income group. Income level of the households alone does not determine the species diversity $\left(r^{2}=0.004, n=98\right)$. However, significant differences are observed in average holding of trees and tree species. Lowest number exists in low-income households. Larger farm size might have supported higher number of trees and tree species in medium and high-income household.

In households where people work outside providing their labor (laborers), the species diversity and species richness is the lowest. This is due to the fact such 
households have small farmland size and are not able to earn subsistence from their farmland alone. Consequently, they have small home garden as well. Therefore, the three factors, farm size, income and home garden size mostly determine the species diversity in the rural farm. As mentioned before, small farm size does not support large number of trees and tree species though highest tree density exists in such type particularly in labor based households.

The linear relationship is also weak between species diversity and forest distance $\left(\mathrm{r}^{2}=0.01, \mathrm{n}=98\right)$. Number of tree holding and tree density is higher in households which are further away from the forested areas. Therefore, in rural farmlands, where agriculture supports the subsistence, households closer to the forest are not worried much about having large number of tree in the farm as they can easily collect their requirements from the nearby forests. However, in some households at a distance from the forests, people have to spend whole day in collecting the household requirements such as fuel, fodder and timber from the forest areas. Therefore, larger the distance from the forests, there is more incentive to plant more trees and with diversity in species.

The data shows that the species diversity and species richness increase as the years of settlement of households increase, but the difference is not significant among the categories. Even the linear relationship between settled time and species diversity is very weak. Late settlers might not have sufficient time to grow and maintain large number of trees. They are still new for the area. But old settlers know quite more about their surrounding and environment. They have crossed the experimental stage to select the best and suited species in the farm while new settlers must start from the beginning. When a household decides to sell the farmland partially or wholly, they exploit the resources from the farm as much as possible before leaving it, which might be the possible reason to have less number of trees and species in late settlers' farms. New settlers generally start the farm from nothing.

In rural Nepal, caste system is still prevalent and that is not an exception in the study area as well. The analysis of survey response to link caste with biodiversity did not show any correlation. The survey found that all households regarded the importance of tree species equally. However, in consistent with earlier findings, if the household with lower caste people have small farm size, small home garden size and low income then they generally have lower diversity and richness of trees in their farm.

\section{Discussion}

The tree species biodiversity at the study site is very low as compared to the similar areas of other south Asian countries particularly the Bangladesh, India and Sri Lanka. Bashar (1999) has found Shanon diversity index of 3.24 for fruit species in Bangladeshi homegardens. Sellathurai (1997) found that for Sri Lanka the index was 3.93. Wide individual distribution of few tree species was the main reason for lower biodiversity. Some households contain higher level of biodiversity compare to all study area. It is therefore very important to consider the household level management for biodiversity conservation.

Das (1999) has found similar result in the farmland of eastern Nepal who has recorded more than 60 species as grown by farmers on their farmland. Carter (1992) recorded 101 tree species in a study conducted in middle hills of Nepal. Rusten (1989) found 127 tree species in the same elevation. It simply reveals that farmland in the hilly region conserve more tree species than the Terai. The Hill farming system is more fragile and sensitive than that of Terai. Hill settlers may need more resources and diversity for security in terms of fodder, fuelwood and land protection. Forest and tree products can be replaced by alternative sources in case of Terai but it is difficult in most part of the hill because of poor transportation and low income. Average tree number per hectare and per household are consistent with the figure mentioned by Karki (1988) in a study conducted in the same physiographic region. He estimated that smallholders planted and maintained an average of 60 trees on land holdings averaging 1.1 ha.

\section{Tree types and their biodiversity}

Species diversity is less important in fuelwood and timber/furniture species. Household concerns are amount, not the diversity in terms of fuelwood and timber requirement while diversity is prime consideration in fodder and fruit species. May be the single tree species can meet the fuelwood requirement of a household. Fuelwood and timber/furniture can be stored after harvest and used later on. Fuelwood can be collected whenever needed.

Unlike fuelwood and timber/furniture trees, species richness is important for fodder and fruit trees. 
Productivity and taste are the prime consideration in case of fruit trees while harvesting season is of concern in fodder trees. Varieties of fruit species satisfy man with different taste in different seasons. Furthermore, not all fruit trees produce good number of fruits and seeds every year and their diversity may compensate such variation. Higher diversity might reduce the risk of production failure of single species. Fruits are also the sources of income in critical situation. It can be sold in the market though it is uncommon in the rural context. Sometime, it can be a matter of pride for household if they please the relatives, visitors, or higher status person serving fruits. Fruit trees are also highly used for shading purposes in the summer as the temperature often soars to 40 degree Celsius in the study area. Fruit trees are mostly planted in nearby home either in the home garden or in the home yard. Some fruit trees such as Artocarpus heterophyllus and Morus alba serve varieties of products at a time. All these factors may explain why rural farmland holds higher fruit species richness.

Different fodder trees are harvested in different seasons. Large number of fodder tree species supports the livestock feeding longer. Green tree fodder is the nutritious feed for stall-fed livestock. Higher diversity of these tree species might supply the fodder resources round the year. In rural areas, where the purchase of livestock feed is out of question due first to non-availability in the nearby places and second due to the cost of feedstock in the main markets, the supply of green fodder becomes the most important nutrient source. As livestock rearing is an integral part of rural communities, sustainability of the rural farming system depends on proper combination of agricultural crop, livestock and tree/forest resources in Nepal.

\section{Socio economic impacts on tree biodiversity}

Since the farmers' priority is agricultural crops, small farm size may not be sufficient to grow large number of trees and species in the same unit of land, even though tree density is higher in such farm. Panday (1987) reports that the farm size holdings are small for afforestation plots and on the other hand, there is no income incentive for tree planting as there is no timber market. The trend shows that the increased homegarden size increases the species diversity and richness continuously. Therefore, complete loss of the system and reduction in size will lead to the loss of tree species diversity unless other socioeconomic factors are changed.

\section{Conclusions}

The present study gives important information about biodiversity related to the tree species in rural households in Nepal. Although the result may not be generalized due to diverse eco-climatic zones in Nepal, the result obtained from this study gives an important conclusion: the level of biodiversity in rural households in Nepal does not depend on one socioeconomic factor. Factors such as landholding size, homegarden size and livestock size have more influence on tree biodiversity than others at household level. Settlements, which depend solely on fodder and fuelwood and are far from the forest areas generally plant large number of trees with varied species. Also, households with large number of livestock generally have large number tree species. The frequent changes of land ownership and their divisions in smaller sizes are the discouraging factor for conservation of tree biodiversity in rural farm level.

\section{References}

Bashar M.A. 1999. Homegarden Agroforestry: Impact on Biodiversity Conservation and Household Food Security. A Case Study of Gazipur district, Bangladesh. M. Sc. Thesis. Agricultural University of Norway.

Brooks T.M., Mittermeier R.A., Mittermeier C.G., Fonseca GAB D.A., Raylands A.B., Konstant W.R., Flick P., Pilgrim J., Oldfield S., Magin G., Hilton-Taylor C. 2001. Habitat Loss and Extinction in the Hotspots of Biodiversity. Conservation Biology 16(4): 909-923.

Carter E.J. 1992. Tree Cultivation on Private Land in the Middle Hills of Nepal: Lessons from Some Villagers of Dolkha District. Mountain Research and Development. 12 (3): 241-255.

Das A.N. 1998. Socio-economics of Bamboos in Eastern Nepal. Ph.D. thesis. Aberdeen University, Scotland, UK.

DFRS. 1999. Forest Resources of Nepal: 1987 - 1998. Publication No. 74. Department of Forest Research and Survey. Kathmandu, Nepal.

Halladay P. and Gilmour D.A. (Eds). 1995. Conserving Biodiversity Outside Protected Areas: Role of traditional agro-ecosystems. IUCN, Gland, Switzerland, and Cambridge, UK. 
Karki J.B.S and Karki M. 1994. Dalbergia: Proceedings of an International workshop. Westley S.B. and Roshetko J.M. (Eds.), Nitrogen Fixing Tree Association. Nitrogen Fixing Tree Research Reports: Special Issue.

Karki M.B. 1988. Impact of multipurpose trees on small-farm systems of Nepal. A Case Study of Karmaiya village.

Margalef R. 1969. Diversity and Stability: A practical proposal and a model of interdependence. Cited in Peter S (1996) Ecology: Theories and Applications. Prentice Hall International Inc. New Jersey, U.S.A.

Mishra S.B. 1998. A compendium on Environment Statistics 1998, Nepal. Central Bureau of Statistics, Kathmandu, Nepal.

Panday K.K. 1987. Some Tenural Aspects of Environmental Problem in Nepal. Raintree J.B. (Eds.), Land, Trees and Tenure. Proceedings of an International Workshop on Tenure Issues in Agroforestry. May 27-31, 1985. ICRAF and Land Tenure Centre, Nairobi and Madison.

Rusten E. 1989. An investigation of an indigenous knowledge system and management practices of tree fodder resources in the middle hills of Central Nepal. Ph.D. thesis, Department of Forestry, Michigan State University, USA. In: Carter E.J. 1992. Tree Cultivation on Private Land in the Middle Hills of Nepal: Lessons from Some
Villagers of Dolkha District. Mountain Research and Development. 12 (3): 241-255.

Sellathurai P. 1997. Homegarden Agroforestry and Sustainability in Kandy District, Sri Lanka. M.Sc thesis. Agricultural University of Norway.

Shannon C.E. and Weaver W. 1949. The Mathematical Theory of Communication. University of Illinois Press, Urbana. In: Stilling P. 1996. Ecology: Theories and Applications. Prentice Hall International Editions. New Jersey, USA.

Stilling P. 1996. Ecology. Theories and Applications. Prentice Hall International Editions. New Jersey, USA.

Soemarwoto O. 1987. Homegardens: a traditional agroforestry system with a promising future. Steppler H.A. and Nair P.K.R. (eds.) Agroforestry: A Decade of Development, pp. 117-140. ICRAF, Nairobi, Kenya.

Wickramasinghe A. 1995. The evolution of Kandyan home-gardens: An indigenous strategy for conservation of biodiversity in Sri Lanka. Halladay P. and Gilmour D.A. (Eds.) Conserving Biodiversity Outside Protected Areas: Role of traditional agroecosystems. IUCN, Gland, Switzerland, and Cambridge, UK. 
Annex 1: Socio economic variables, their categorization and sample distribution of the study area

\begin{tabular}{|c|c|c|c|c|}
\hline $\mathrm{SN}$ & Variables and unit & Category & Range & Sample \# \\
\hline \multirow{3}{*}{1} & \multirow{3}{*}{ Farm size (Katha) } & Small & $<=15$ & 47 \\
\hline & & Medium & $>15-<=45$ & 40 \\
\hline & & Large & $>45$ & 09 \\
\hline \multirow{3}{*}{2} & \multirow{3}{*}{ Home garden size (Katha) } & Small & $<=1$ & 62 \\
\hline & & Medium & $>1-<=2$ & 28 \\
\hline & & Large & $>2$ & 08 \\
\hline \multirow{3}{*}{3} & \multirow{3}{*}{ Livestock size (LU) } & Small & $<=2$ & 23 \\
\hline & & Medium & $>2-<=5$ & 38 \\
\hline & & Large & $>5$ & 37 \\
\hline \multirow{3}{*}{4} & \multirow{3}{*}{ Fuelwood consumption $(\mathrm{Kg})$} & Low & $<=1500$ & 37 \\
\hline & & Medium & $>1500-<=2250$ & 41 \\
\hline & & High & $>2250$ & 20 \\
\hline \multirow{3}{*}{5} & \multirow{3}{*}{ Income Class (NRs./year) } & Low & $<=50,000$ & 57 \\
\hline & & Medium & $>50,000-<=100000$ & 33 \\
\hline & & High & $>1,00,000$ & 08 \\
\hline \multirow{3}{*}{6} & \multirow{3}{*}{ Forest distance (Minutes) } & Near & $<=15$ & 41 \\
\hline & & Medium & $>15-<=45$ & 40 \\
\hline & & Far & $>45$ & 17 \\
\hline \multirow{3}{*}{7} & \multirow{3}{*}{ Settlement period (Years) } & New & $<=5$ & 08 \\
\hline & & Middle & $>5-<=10$ & 13 \\
\hline & & Early & $>10$ & 77 \\
\hline
\end{tabular}

Unit conversion

1. 1 Hectare $=$ nearly equal to 30 kattha

2. 1 Cow $=1 \mathrm{LU}, 1$ Buffalo $=1.5 \mathrm{LU}$ and 1 Goat $=0.6 \mathrm{LU}$

3. 1 US $\$=$ NRs. 68 